\title{
Prediction Reliability of the Building Components as a Model Based on the Distribution of Weibull
}

\author{
Beata Nowogońska \\ Institute of Building Engineering, University of Zielona Góra, Zielona Góra, 65-516, Poland.
}

Received: February 21, 2015 / Accepted: March 22, 2015 / Published: August 25, 2015.

\begin{abstract}
All technical objects are at risk of damages during the consecutive years of their usage. Reliability of an object is an essential issue during its usage. The main problem is the strive to eliminate damage formation. Predicting the reliability of an object should allow qualitative and quantitative analysis of the possibility of occurrence of unfavorable events. The adaptation of mathematical models describing the degradation processes in mechanical and electronic devices creates opportunities to develop diagnostic standards for buildings erected in traditional technology. The article presents the methodology of prediction of reliability of a building, and the values of performance features are defined by the parameters of the Weibull distribution function.
\end{abstract}

Key words: Weibull distribution, reliability prediction, degree of technical wear

\section{Introduction}

All technical objects suffer breakdowns and damages with the passage of time. The main problem arising while buildings are in use is their reliability and the endeavor to eliminate the formation of any damages. The presented analysis includes apartment buildings erected in a traditional technology and regards them as technical objects. For such approached buildings it is proposed to apply rules applied for mechanical and electrical objects. For the needs of the reliability analysis of apartment buildings erected in a traditional technology, a building was divided into components which were analyzed first separately and then together in the whole building. The probability of the exploitation of a building without any breakdowns in a given period of time is defined as exploitation reliability.

A complex analysis of building reliability should include phenomena accompanying long-time exploitation of a building. The following criteria are used for the reliability estimation: the wear, the

Corresponding author: Beata Nowogońska Ph.D., Institute of Building Engineering, University of Zielona Góra, Poland. E-mail: b.nowogonska@ib.uz.zgora.pl. frequency of maintenance works, the way of exploitation, the influence of external factors, the propriety of the project process, the quality of materials, the precision of the building erection works. In case of buildings older than 100 years there are no possibilities to examine the three last factors. For a long period of exploitation, it can be assumed that designing processes and erection works were performed correctly and the used materials were of high quality. It was also assumed that the way of exploitation and the influence of external factors for all buildings were on the same level, and did not condition the differences in building reliability and thus, they were neglected in the analysis.

\section{Review on the State of Art on Reliability}

All technical objects are at risk of damages during the consecutive years of their usage. Reliability of an object is an essential issue during its usage. The main problem is the strive to eliminate damage formation. Predicting the reliability of an object should allow qualitative and quantitative analysis of the possibility of occurrence of unfavourable events. Issues related to the reliability of technical objects are presented both 
in the literature on exploitation of mechanical, electrical, electronic appliances and building structures.

A. Nowak [20], who deals with reliability in the design and analysis of structures, defines reliability as the ability to perform certain requirements (load-bearing capacity, stability, usability, durability, etc.) within an assumed period of usage. He provides indicators of reliability, designed to achieve the appropriate level of the target on an example of bridges. Methods for reliability analysis uncover the real safety reserves in structures.

Frankel [8] defines reliability as probability of non-occurrence of any of the unacceptable ultimate states of a whole structure and its components in the assumed operational period. Also according to $\mathrm{J}$. Murzewski [17], the reliability is defined as the probability of non-occurrence of any damage to a device or a system during its exploitation in time period $t$, in certain conditions and environ. Unlike quality, reliability is dependent on time - quality is evaluated when an object is being put into use, whereas reliability - during its exploitation period. Reliability is connected with durability which is a measure of the reliability of systems. J. Murzewski defines reliability function $Q(t)$ as the survival function, which decreases with time. L. Runkiewicz [22] conducted a wide range of research related to the reliability of reinforced concrete structures. He defines reliability as a ratio of the number of failures to the number of constructed and exploited buildings. P. H. Emmons, A.M. Vaysburd [6] presented the course of the reliability of reinforced concrete structures and also associated problems of repair planning.

S. Woliński [28] widely presented issues related to the reliability of building structures. The author presented a complete historical overview of research on the safety of building structures, explained the levels of assurance of reliability, as well as probabilistic theories and methods of fuzzy safety standards of a structure. S. Woliński defines reliability in a general context as the ability of a structure to perform the designed functions within a certain time of its exploitation (the condition of a structure) and in mathematical context - as the probability of failure of a structure to maintain certain states within an assumed period of exploitation. The sufficient reliability of a structure is achieved when any damage to an object or an end of its further exploitation result in economically and socially acceptable consequences and when there is sufficiently small probability of any hazards to life and health.

J. Wysokowski is the author of numerous publications on the durability of road bridges, their reliability, and in [29] he presented the results of his studies in the form of curves of object degradation. $\mathrm{J}$. Bucior [2] defined reliability for mechanical objects as the probability that the object will be usable in time $(0$, t). The author evaluated quantitatively the reliability of an object with the use of indicators which include the properties of the object, the method and conditions of exploitation. B. S. Sotskow in [24], presented fundamentals of the theory of reliability of components of automatics and presented the methodology of the reliability analyses of various components and systems of automation equipment. S. Niziński [19], understands a technical object as a subject of diagnosis. He believes that the rational exploitation of technical appliances is possible only after the exploitation characteristics of an object are known.

The essence of the wear of objects, by C. Cempel [3], is an increase in damage and partial defects. A prognostic ally elaborated curve of life of a vibro-acoustic machine is based on the reliability of symptoms. T. Nowakowski [15] analysed the research on the reliability of mechanical objects, mainly vehicles and machines, on the basis of which he developed its own computerised advisory system. J. Migdalski [13] approaches reliability as an interdisciplinary problem due to the complexity of modern technical facilities, which are systems 
containing electrical, mechanical, electronic components and other. The subject of reliability is approached complementary in all phases of the object existence.

A joint committee of CIB and RILEM has produced a report [16] which analyses the shortcomings of much durability testing, identifies the problems facing reliable service life prediction, offers a methodology for approaching those problems and lists the key research needs.

\section{Mathematical Model of Reliability}

In the theory of reliability, the distribution of a product life-span is most frequently understood as the Weilbull distribution of a random variable of time of object usability ([12], [17], [19], [20], [21], [23], [24], [26], [30]). The probability density function for the Weibull distribution is determined with the relation:

where:

$$
f(t)=\alpha \cdot \beta^{\alpha} \cdot t^{\alpha-1} \exp \left[-(\beta t)^{\alpha}\right] \text { for } t \geq 0
$$

$t$ is the exploitation period,

$\alpha$ - scale parameter (a real number) when $\alpha>0$,

$\beta$ - the shape parameter (a real number) when $\beta>0$.

Parameter $\alpha$ of the distribution determines the probability of a breakdown in time:

- for $\alpha<1$, the probability of breakdown decreases in time, which suggests that, when the object breakdown is modeled, some specimen may have production defects and slowly fall out of the population;

- for $\alpha=1$ (exponential distribution), the probability is constant, it indicates the fact that breakdowns are caused by external random events;

- for $\alpha>1$, the probability grows in time, which suggests that time-related technical wear of elements is the main cause of breakdowns;

- for $\alpha=2$ (the Rayleigh distribution), the probability grows linearly in time.

Distribution parameter $\beta$ is a coefficient characterising the rate of the reliability obsolescence:

$$
\beta=1 / T_{R}
$$

$T_{R}$ denotes the period of the object durability.

The analysis of numerous physical phenomena may often lead to a conclusion that some properties change randomly and, at the same time, depend on other parameters' changes. A mathematical model of such phenomena goes far beyond the classical theory of probability, where only random events and random variables are considered. The extension of the probability theory which allows the examination of random events in connection with a certain parameter (e.g. time) is the theory of stochastic processes.

The distribution function for the Weibull distribution obtained after integration:

$$
F(t)=1-\exp \left[-(\beta t)^{\alpha}\right]
$$

In the literature, the distribution function is called the probability of damage, a destruction function, breakdown or a failure function and is determined with the relation:

$$
F(t)=P\left(t<T_{R}\right)=1-R(t)
$$

$T_{R}$ is the period of object durability and $R(t)$ is the reliability function, also called the probability of proper operation, or durability function.

Inefficient or failure-free operations are opposite events that exclude one another, therefore, Eq. (4) may be applied.

The object's reliability is defined as the ability to fulfil the task resulting from the purpose that it was intended for. It means that the object is demanded to fulfil a determined function in determined time $t$ in determined conditions of operation. The measure of the reliability of an object, in terms of the task, is the probability of the task completing. Such determined reliability measure is a function of time of the building's reliable performance and is called reliability function.

Exponential distribution is a particular case of the Weibull's distribution, where shape parameter $\alpha=1$. Exponential distribution is frequently used in the examination of a proper performance time [2], [19], [23]. The relation defining the reliability functions for the $i$-th component of a building for known 
parameters $\alpha$ and $\beta$ may take the form:

$$
R_{i}(t)=\exp \left[-\left(t / T_{R i}\right)\right]
$$

$R_{i}(t)$ is the exploitation reliability for the $i$-th component of a building, $t$ is the exploitation time and $T_{R i}$ is the durability period of the $i$-th element of a building.

Another particular case of Weibull distribution, where $\alpha=2$ is the Rayleigh distribution. The application of the Rayleigh distribution for buildings seems to be the best choice. All buildings and their components are subject to technical wear and the Rayleigh distribution is applied when the object's wear increases in time [21]. For this case, the reliability function takes the form:

$$
R_{i}(t)=\exp \left[-\left(t / T_{R i}\right)^{2}\right]
$$

\section{Reliability Prediction of Building Components}

The research included the specification of building components which were first analyzed separately and then together in the whole building. Each component is made of various building materials. Over time, all materials are subject to ageing and natural wear, and lose their original exploitation properties. The process is different for each building component and they are all characterized by their own durability periods.

To determine the exploitation reliability of a building with the use of Eq. (6), the building, erected in the traditional technology, was divided into 25 components. A determined material-structure solution with characteristic theoretical average durability periods $T_{R i}\left(T_{R i}\right.$ by Ref. [25]) was assumed for each component. Eq. (6) was applied to examine the change in the exploitation reliability of all the components within the assumed a 100-year period of exploitation. The selected results of calculations are presented in Figs. 1-6.

Methods derived from the theory of exploitation of machines and electrical appliances were applied to examine the properties of apartment buildings. The

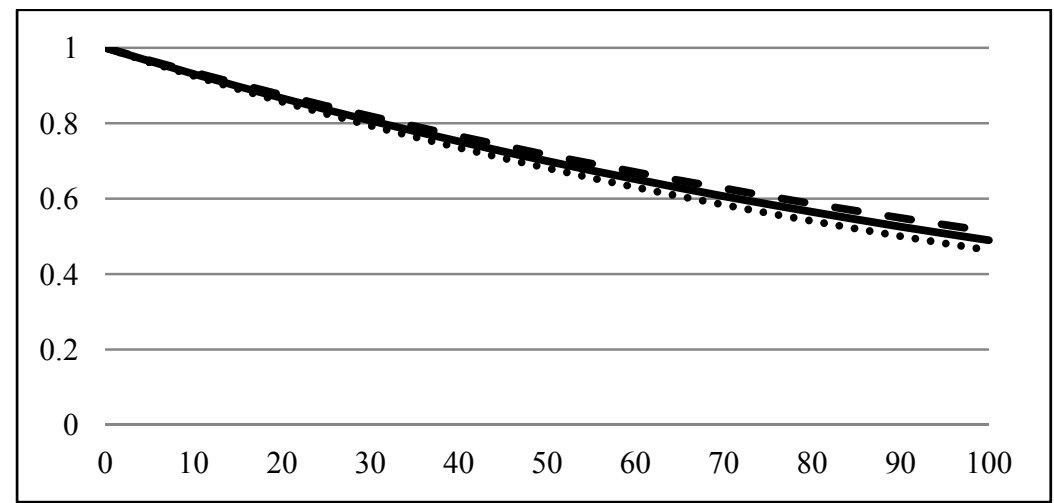

Fig. 1 Reliability prediction of masonry walls according to the exponential distribution.

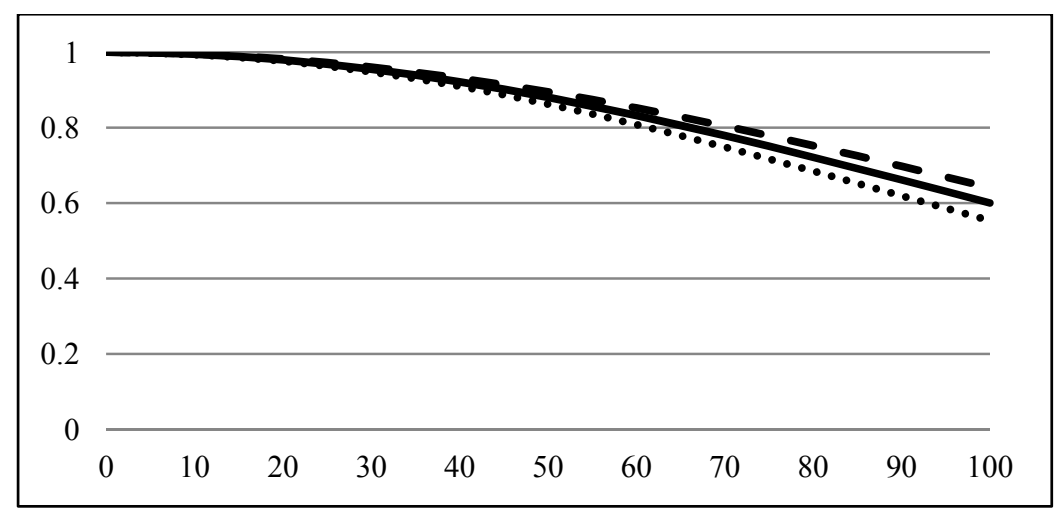

Fig. 2 Reliability prediction of masonry walls according to the Rayleigh distribution 


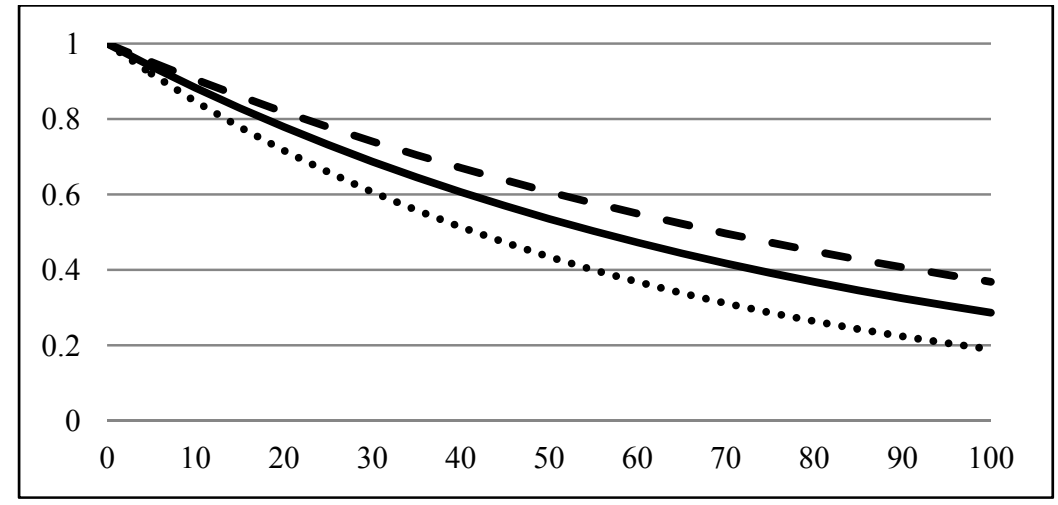

Fig. 3 Reliability prediction of wooden rafter according to the exponential distribution.

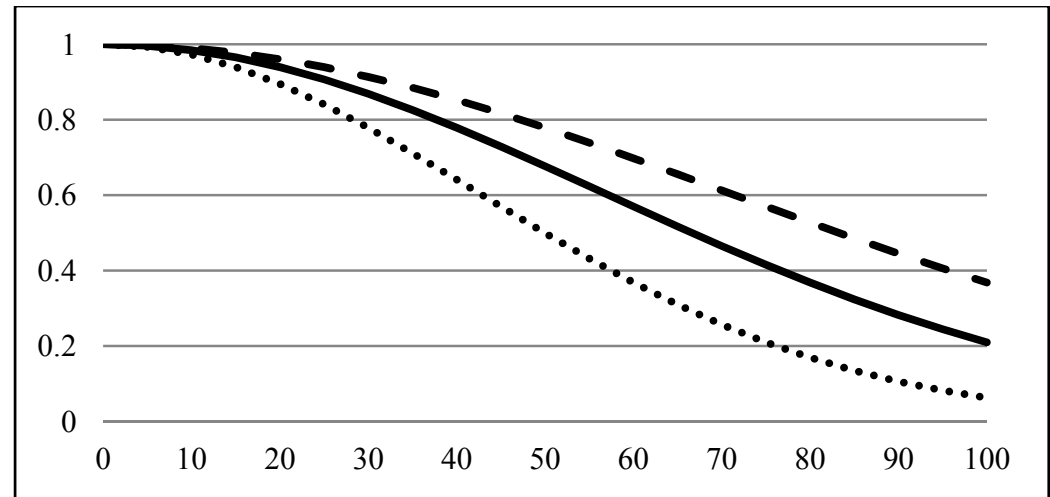

Fig. 4 Reliability prediction of wooden rafter according to the Rayleigh distribution.

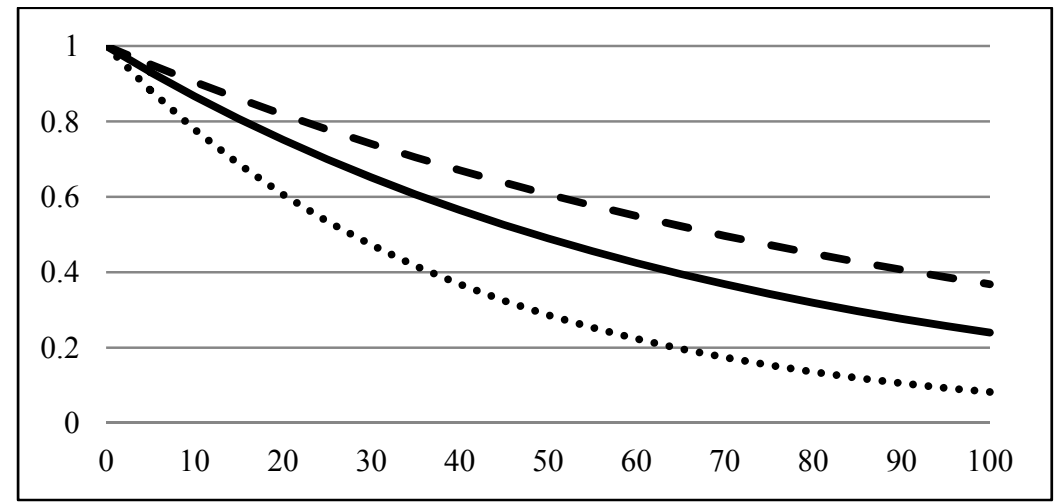

Fig. 5 Reliability prediction of plain tiles according to the exponential distribution.

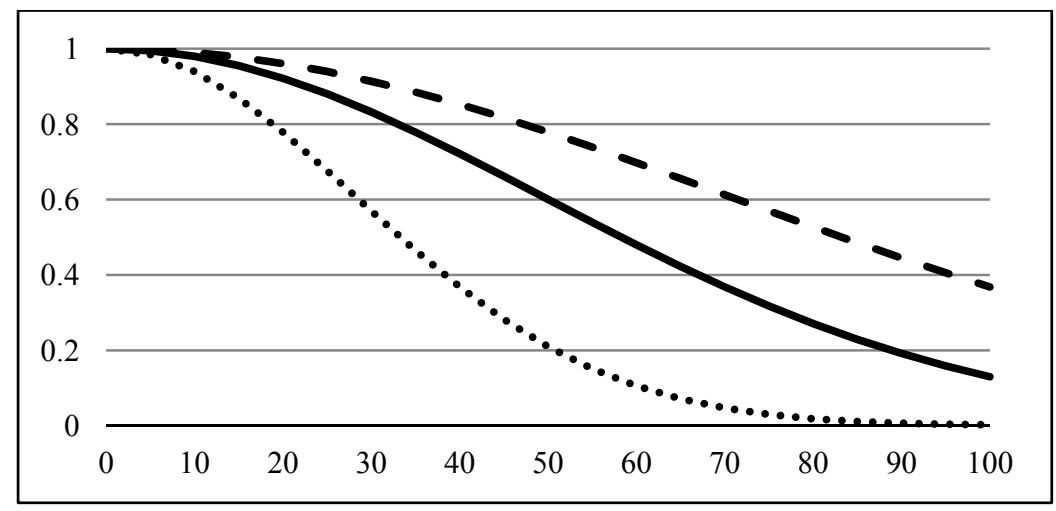

Fig. 6 Reliability prediction of plain tiles according to the Rayleigh distribution. 
results obtained at the present stage of the realisation of the exploitation reliability problem may be helpful in maintenance planning.

\section{Verification of the Mathematical Model}

The bibliography on reliability of electronic ([23]) a device attributes the intensity of failure to technical wear as described in (8):

$$
S_{z}=\int_{0}^{t} l(t) d t
$$

where $S_{z}$ - the rate of the product wear.

The technical wear according to the exponential distribution, where the intensity of failure is constant (8) is expressed with a linear function:

$$
S_{Z}=t / T_{R}
$$

$S_{z}$ : the degree of technical wear of an object expressed in percentage,

$t$ : the age of the object,

$T_{R}$ : the expected durability period of an object expressed in years.

The obtained relation is one of the time methods applied for the determination of technical wear of carelessly maintained buildings in an arbitrary period of time.

For the Rayleigh distribution, where $\alpha=2, \beta=1 / T_{R}$, the degree of technical wear equals:

$$
S_{Z}=t^{2} / T_{R}^{2}
$$

The examined material comprises 260 residential buildings performed in the traditional technology, situated within the area of the town of Gorzow Wlkp. (Lubuskie Voivodeship in Poland). The applied building materials and the structural solutions are similar in all the buildings. The masonry walls were made of solid bricks; the floors over the ceilings masonry, Klein type; the remaining floors - wooden beams; the stairs and the roof structure - wooden, rafter framing - purlin-collar-tie type and in some cases - collar-beam type; roofing - flat tiles or roofing paper.

The technical states of all the buildings were periodically inspected by experts. The periodic monitoring, consisting in the examination of technical wear, resulted in the reports containing the information on the percentage wear of 25 components of the buildings. For each building element, it is possible to determine the prediction of the technical wear in any arbitrary exploitation period. The durability periods of building elements of determined material-structure solutions are given in, and after substituting them into formulas (9) and (10), the prediction of the degree of technical wear may be obtained according to the exponential distribution and the Rayleigh distribution.

For brick masonry walls, the durability period is determined within the limits $130-150$ years. The degrees of technical wear were determined for the minimum (130) and the maximum (150) values, with the use of the exponential distribution (formula 9) and according to Rayleigh distribution (formula 10).

Average values of technical wear of load-bearing walls of buildings in Gorzów were also marked in order to verify the proposed methods [21]. It is possible to determine the current year of its exploitation after having known the time of the building erection. The values of the degree of wear of the walls by the Rayleigh distribution were verified using student test. Assuming a 5\% chance of error in applying $(p=0.05)$, and the number of degrees of freedom is 19 , the critical value of the test is 2.0930 . The test result in the study was 2.16817 , which means that the results are statistically significant for the level of $p=0.05$.

\section{Conclusion}

Methods derived from the theory of exploitation of machines and electrical appliances were applied to examine the properties of apartment buildings. The results obtained at the present stage of the realization of the exploitation reliability problem may be helpful in maintenance planning. In order to program the repair and renovation works, the prognostic 
determination of the scope of work in terms of the kind and quantity is necessary. The repairs should include preventive actions aiming at assuring that no damages will occur to the building. The reliability analysis may be applied for predicting the dates of the repairs of the components of a building erected in the traditional technology. The course of the exploitation reliability of elements over the subsequent years of their exploitation may be used in prognostic planning of inter-repair cycles for the whole building.

\section{References}

[1] Andrews, J. D., Moss, T. R. Reliability and Risk Assessment. New York: John Wiley 1993.

[2] Bucior J. Fundamentals of reliability. Publisher Rzeszow University of Technology 1989.

[3] Cempel C., Natke H., Damage Evolution and Diagnosis in Operating Systems. In Safety Evaluation Based on Identification Approaches Related to Time-Variant and Nonlinear Structures. Germany: Vieweg+Teubner Verlag, 1993.

[4] Cordeiro, G., Ortega, M., and Lemonte, A. The Exponential-Weibull Lifetime Distribution, Journal of Statistical Computation and Simulation 2013, 84 (12) $1-15$.

[5] Corner P. 11th Advances in Reliability Technology Symposium. Elsevier Applied Science, Barking 1990.

[6] Emmons P. H., Vaysburd A. M. System concept in design and construction of durable concrete repairs. Construction and Building Materials, 1996, 10 (1), pp. 69-75.

[7] Fouchera, B., Boulliéa, J., Mesletb, B., and Dasb, D. A Review of Reliability Prediction Methods for Electronic Devices, Microelectronics Reliability 200242 (8): 1155-62.

[8] Frankel, E. G. Systems Reliability and Risk Analysis. Netherlands: Springer 1984.

[9] Khelassi, A., Theilliol, D., and Weber, P. 2011. Reconfigurability Analysis for Reliable Fault-Tolerant Control Design. International Journal of Applied Mathematics and Computer Science 21 (3) 2011: 431-9.

[10] Knyziak P. Analysis of the technical state for large-panel residential buildings using artificial neural networks, 17th International Conference On The Application Of Computer Science And Mathematics In Architecture And
Civil Engineering, Weimar, Germany, 12 14.06.2006, p. 36.

[11] Kolowrocki, K. On Limit Reliability Functions of Large Systems. Part I. Statistical and Probabilistic Models in Reliability. Boston: Birkhäuser Boston 1999.

[12] Masters L. W., Brandt E. Systematic Methodology for Service Life Prediction of Building Materials and Components. Materials and Structures nr 22/1989.

[13] Migdalski J. Reliability engineering, ZETOM Warszawa 1992.

[14] Moan, T. Life-Cycle Assessment of Marine Civil Engineering Structures. Structure and Infrastructure Engineering: Maintenance, Management, Life-Cycle Design and Performance 2007-7: 11-32.

[15] Młynczak, M., and Nowakowski, T. Rank Reliability Assessment of the Technical Object at Early Design Stage with Limited Operational Data-A Case Study. International Journal of Automation and Computing 2006 -3 (2): 169-76.

[16] Moubray, J. RCM II-Reliability Centred Maintenance. Oxford: Industrial Press 2007.

[17] Murzewski J. Reliability engineering structures Arkady, Warszawa 1989.

[18] Nireki T. Service life design. Construction and Building Materials, Vol. 10, No 5, 1996 Elsevier Science Ltd, Printed in Great Britain 1996.

[19] Nizinski S., Pelc H. Diagnosis of mechanical equipment. Publisher of Science and Technology, Warszawa 1990.

[20] Nowak A. S., Collins K. R. Reliability of Structures, Mc Graw-Hill Int. Edition 2000.

[21] Nowogońska B. Model of the Reliability Prediction of Masonry Walls in Buildings Journal of Mechanics Engineering and Automation 4 (2014) 975-980.

[22] Runkiewicz, L. Evaluation of the Quality of Materials in Historic Buildings. Presented at the IV Conference on Scientific and Technological Sciences and PZITB on "Engineering Problems of the Old Town Historic Restoration", Cracow 1988.

[23] Salamonowicz T. Models reliability serviceable objects of preventive service. The Journal Issues machine operation, issue 2/2001.

[24] Sotskow B. S. Reliability of components and automation equipment. Publisher of Science and Technology, Warszawa 1973.

[25] Ścislewski Z. Life Building. Kielce: Kielce University of Technology Press, Kielce 1995.

[26] Walpde R. E., Myers R. H. Probability and Statistics for Engineers and Scientists, Macmillan Publishing 
Company, London 1985.

[27] Winniczek W. Valuation of buildings and structures from reconstruction approach CUTOB-PZITB, Wrocław 1993.

[28] Woliński Sz, Statistics and Reliability, University of Technology Rzeszów 2001.

[29] Wysokowski A. Effect of fatigue on the durability of steel highway bridges, Archives of Civil Engineering 2002, Vol. 48, no 1, s. 59-91.

[30] Zaidi A., Bouamama B., Tagina M. Bayesian reliability models of Weibull systems: state of the art. International Journal of Applied Mathematics and Computer Science, 2012, vol. 22, no 3, pp. 585-600. 